\title{
Communication \\ Variability in the Chemical Composition of a New Aromatic Plant Artemisia balchanorum in Southern Russia
}

\author{
Gennadii V. Khodakov ${ }^{1}$, Lavr A. Kryukov ${ }^{2,3}$ (D) Einat Shemesh-Mayer ${ }^{4}$ and Rina Kamenetsky-Goldstein ${ }^{4, *(D)}$ \\ 1 V.I. Vernadsky Crimean Federal University, Agro-Technological Academy, 295007 Simferopol, Russia; \\ gennadii-hodakov@mail.ru \\ 2 V.I. Vernadsky Crimean Federal University Center for Advanced Scientific and Technological Development, \\ 295007 Simferopol, Russia; lavrkryukov@gmail.com \\ 3 Institute of Biology and Biomedicine, Lobachevsky State University of Nizhni Novgorod, \\ 603022 Nizhni Novgorod, Russia \\ 4 The Agricultural Research Organization, Volcani Center, Institute of Plant Sciences, \\ Rishon LeZion 7505101, Israel; shemeshe@volcani.agri.gov.il \\ * Correspondence: vhrkamen@volcani.agri.gov.il
}

check for updates

Citation: Khodakov, G.V.; Kryukov,

L.A.; Shemesh-Mayer, E.;

Kamenetsky-Goldstein, R. Variability in the Chemical Composition of a

New Aromatic Plant Artemisia

balchanorum in Southern Russia.

Plants 2022, 11, 6. https:/ /doi.org/ $10.3390 /$ plants 11010006

Academic Editors: Claudia Giuliani and Fico Gelsomina

Received: 20 October 2021

Accepted: 16 December 2021

Published: 21 December 2021

Publisher's Note: MDPI stays neutral with regard to jurisdictional claims in published maps and institutional affiliations.

Copyright: () 2021 by the authors. Licensee MDPI, Basel, Switzerland. This article is an open access article distributed under the terms and conditions of the Creative Commons Attribution (CC BY) license (https:/ / creativecommons.org/licenses/by/ $4.0 /)$.

\begin{abstract}
Lemon wormwood Artemisia balchanorum was recently introduced to southern Russia as a new aromatic plant. Based on biological and chemical characteristics, several populations with dominant citral, linalool, and geraniol production were selected for further development and maintained by seed propagation. Chemical analysis of five outstanding populations at three stages of annual development: vegetative, flower buds, and full flowering, confirmed that the seed populations retain the distinct dynamics of the dominant and minor components during the annual cycle and can be used for the commercial production of citral, linalool, and geraniol. Micropropagation in vitro allows for efficient clonal micropropagation and mass reproduction of elite cultivars and promising forms of $A$. balchanorum on a commercial scale but cannot serve as a source of direct and efficient production of secondary metabolites.
\end{abstract}

Keywords: lemon wormwood; citral; linalool; geraniol

\section{Introduction}

Plants of the genus Artemisia L. (Asteraceae) have long been used in folk medicine and cuisine in many countries around the world. They contain biologically active substances that serve as the basis for the development of new drugs, some of which are already in use clinically [1,2]. In addition, Artemisia species have a high nutritional value. They are used as spices, seasonings, and aperitifs; as dyes for Chinese Qingtua dishes; for flavoring cakes, vinegars, alcoholic beverages, and tobacco; and consumed in the form of herbal tea and salads [3]. The biological significance of Artemisia stems from its complement of natural compounds: terpenoids (mainly monoterpenes of essential oils) and sesquiterpene lactones, flavonoids, lignans, alkaloids, steroids, phenolic acids, and coumarins [4,5], all of which are well known for a wide range of biological activities.

Similar to other aromatic plants, the most important chemical compounds of Artemisia for commercial production and for use in the cosmetic and pharmaceutical industries are essential oils [6]. Aromas, flavors, and medicinal benefits of the essential oils depend on their main organic compounds-terpenes [7,8]. In Artemisia spp., these include citral, with a strong citrus aroma; linalool, with a pleasant floral aroma and an antibacterial effect [9]; and geraniol, with a floral-fruit aroma and antibacterial and antifungal effects [10]. Citral is found in the oils of lemon myrtle, lemongrass, lemon tea tree, lime, and lemon. Citral is either a pair or a mixture of terpenoids with the molecular formula $\mathrm{C}_{10} \mathrm{H}_{16} \mathrm{O}$. The two compounds are geometric isomers: the $E$-isomer is known as geranial (trans-citral), while the Z-isomer is known as neral (cis-citral). Linalool is a major constituent of the essential oils of coriander, cymbopogon, sweet orange flowers, lavender, and sweet basil, among 
others. Its odor is similar to floral, spicy wood and has a light citrus-like flavor. Geraniol is the primary component of the essential oils of citronella, rose, and palmarosa [11]. In addition to its pleasant aroma, geraniol exhibits insecticidal and repellent properties and is used as a pest control agent with low toxicity [12].

Synthesis and accumulation dynamics of aromatic compounds are regulated at different development stages by circadian rhythm and biological and abiotic factors $[13,14]$. The harvest stage can significantly affect the biochemical content. Therefore, from a practical point of view, the study of secondary metabolite composition and accumulation during the plant growth cycle will help to determine the optimal harvesting period for the specific compounds. When young annual stems are harvested in spring, this process eradicates flower development. At the same time, in many aromatic and medicinal plants, the best essential oils are accumulated at the stages of flower buds and full flowering $[15,16]$. Therefore, metabolite profiling of the chemical composition and oil content at different developmental stages is critical for the optimization of the harvest period for the desirable products.

Lemon wormwood (Artemisia balchanorum Krasch.) was introduced to the south of Russia from its natural habitats in the deserts and semi-deserts of Central Asia. Its chemical composition has been evaluated for cultivation as a desirable new aromatic crop and an alternative source for essential oils that are currently important to Russia. In Asia, this perennial semi-shrub with glaucous leaves and paniculate inflorescences is used in cooking and folk medicine [17]. The plants contain natural mono- and sesquiterpenes of essential oils, diterpene (phytol), triterpenes, and other useful compounds [18-20]. The selection for the specific biological and chemical traits in a large population of $A$. balchanorum has led to the development of several rather homogeneous lines with valuable qualities. These lines are currently maintained by seed propagation and can be used for commercial purposes. However, seed propagation of $A$. balchanorum is not always efficient due to a low rate of germination after seed storage. Propagation by lignified cuttings is used in commercial production, but the low (15-40\%) survival rate of cuttings hinders the efficiency of agricultural production [21]. Difficulties inherent to traditional A. balchanorum breeding create problems preserving the genetic identity of promising genotypes when attempting to intensify the breeding process and enlarge the scale of replication. Therefore, in addition to the usual methods of reproduction of promising genotypes, attempts were made to propagate $A$. balchanorum using an in vitro culture method [22].

In this study, we identified and compared the chemical profiles of the selected seed populations of $A$. balchanorum at three stages of their annual development, from the vegetative stage in spring to full flowering in November. The results will be used in the future selection and propagation of new and promising Artemisia cultivars and to determine the optimal harvesting period for a high concentration of specific aromatic compounds.

\section{Results and Discussion}

The values of the mass fractions of the essential oils in terms of raw and dry weight for all plants studied during the spring shoot regrowth (Table 1) indicate that the most productive cultivars regarding the amount of essential oils are 136 and 150, with values of $1.43 \%(3.88 \%)$ and $1.64 \%(4.54 \%)$, respectively. Cultivar 210 yielded the lowest amount, $0.37 \%(1.08 \%)$. For oils distilled from plantlets of 130 obtained in vitro, the content of essential oil was low $(0.04 \%)$.

Chromatographic analysis revealed more than 40 compounds, 16 of which were identified as myrcene, 1,8-cineole, $\alpha, \gamma$-terpineol, $\alpha$ thujone, linalool, $\beta$-thujone, camphor, borneol, citronellal, neral (cis-citral), geraniol, geranial (trans-citral), oxycitronellal, geranyl acetate, and geranylpropionate. Among these, linalool, cis-citral, geraniol, trans-citral, and geranyl acetate are dominant (Tables S1 and S2). 
Table 1. Percentage of the fraction of essential oils in fresh and dry samples of five lines of A. balchanorum (vegetative stage). One-way ANOVA and Student's $t$-test analyses were applied. Levels not connected by the same letter are significantly different $(\alpha=0.05)$.

\begin{tabular}{cccc}
\hline $\begin{array}{c}\text { Cultivar } \\
\text { Number }\end{array}$ & $\begin{array}{c}\text { Content in Fresh } \\
\text { Mass (\%) }\end{array}$ & $\begin{array}{c}\text { Dry Weight } \\
\mathbf{( \% )}\end{array}$ & $\begin{array}{c}\text { Content in Dry } \\
\text { Mass (\%) }\end{array}$ \\
\hline 130 & $0.65 \mathrm{~d}$ & $34.03 \mathrm{a}$ & $1.91 \mathrm{~d}$ \\
\hline 192 & $1.17 \mathrm{c}$ & $34.61 \mathrm{a}$ & $3.38 \mathrm{c}$ \\
\hline 210 & $0.37 \mathrm{e}$ & $34.26 \mathrm{a}$ & $1.08 \mathrm{e}$ \\
\hline 136 & $1.43 \mathrm{~b}$ & $36.86 \mathrm{a}$ & $3.88 \mathrm{~b}$ \\
\hline 150 & $1.64 \mathrm{a}$ & $36.12 \mathrm{a}$ & $4.54 \mathrm{a}$ \\
\hline
\end{tabular}

A comparative analysis of essential oils of all cultivars in three developmental stages is shown in Figures 1 and 2. Most of the compounds showed significant statistical interaction between the cultivar and the developmental stage (Table S3). In other aromatic plants, e.g., Cymbopogon spp. [23], esterification processes are prevalent in the tops of the shoots during spring regrowth. Biosynthetic chains from geraniol are acetylated with acetyltransferase and then de-acetylated to yield geranyl acetate. In A. balchanorum, while geranyl acetate was found at all stages of plant development, it predominated in the vegetative stages (Figure 1). For instance, in cultivar 130, geranyl acetate comprised more than $50 \%$ of the main essential oils observed during the vegetative stage, while linalool became dominant at the flower bud stage (58\%) and citrals $(63 \%)$ during flowering. Geranyl acetate dominates during the first stage in all cultivars, but at the stages of flower buds and flowering, geraniol dominated in 192 and 210, while citrals increased in 130, 210 136, and 150.

Differences between stages in each cultivar were also observed in the presence of minor economically important components-1,8-cineol and camphor (Figure 2).

We found that cultivar 130 can serve as a rich source of natural citrals, a valuable product, which can be extracted directly from plant material at the flowering stage. Similarly, Artemisia santonica f. citralifera has been proposed as an efficient producer of natural citrals, with the highest content (44.6\%) found during the flowering stage [24]. These lemonscented monoterpenes are largely used in food and cosmetics, and A. balchanorum can serve as an additional source for their efficient extraction. Linalool (3.6\%) and geraniol $(10.6 \%)$ were found in the cultivar 130 during the flowering stage, along with a significant amount of geranyl acetate $(8.5 \%)$. The sharp increase in the content of citrals during flowering (Figure 1) indicates weakened esterification and increased oxidation due to the activation of geranyl dehydrogenase [25].

Another valuable compound, linalool, can be extracted from this cultivar in the flower bud stage when its content reaches $50 \%$ of the total amount of essential oils. Linalool possesses a comprehensive range of bioactive properties, which can be exploited for pharmaceutic and cosmetic applications [26]. In addition to these major compounds, cultivar 130 contains the valuable minor components 1,8-cineole and camphor (Figure 2). The content of 1,8-cineole, which increases from $0.18 \%$ during spring regrowth to $0.42 \%$ at the flower bud stage, decreases to $0.13 \%$ during the mass flowering period. The content of camphor during the growing season gradually increases from $0.03 \%$ to $0.32 \%$. 

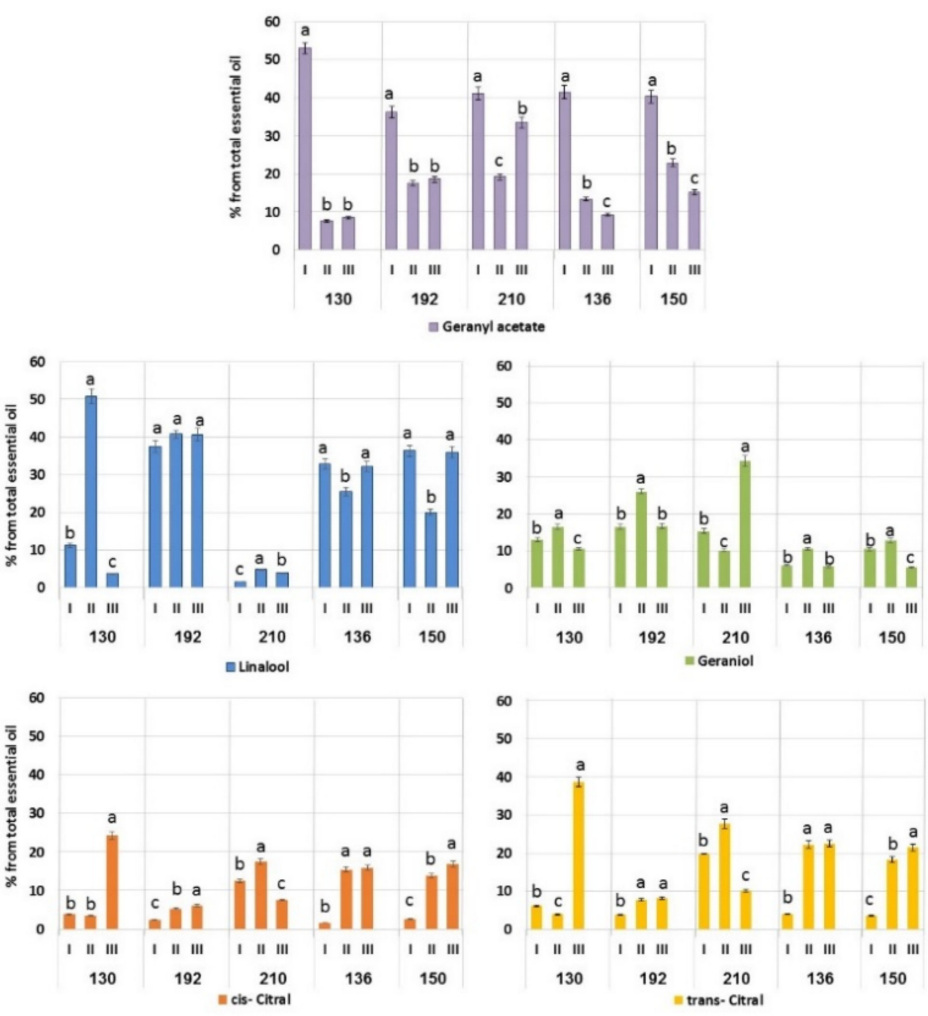

Figure 1. Accumulation of dominant components in the essential oil of cultivars 130, 192, 210, 136, and 150 of $A$. balchanorum at three stages of development, shown as a percentage from the total amount of essential oil. I-vegetative stage: during the spring regrowth at the end of May 2019, the entire annual shoots were sampled; II-flower buds: the tops of the stems with closed buds were sampled in mid-October 2019; III-flowering: the tops of the stems with inflorescences were sampled in mid-November 2019. Each dominant compound was analyzed separately in each cultivar for the differences between the stages. Bars represent standard deviation. One-way ANOVA and Student's $t$-test were applied. Levels not connected by the same letter are significantly different $(\alpha=0.05)$.
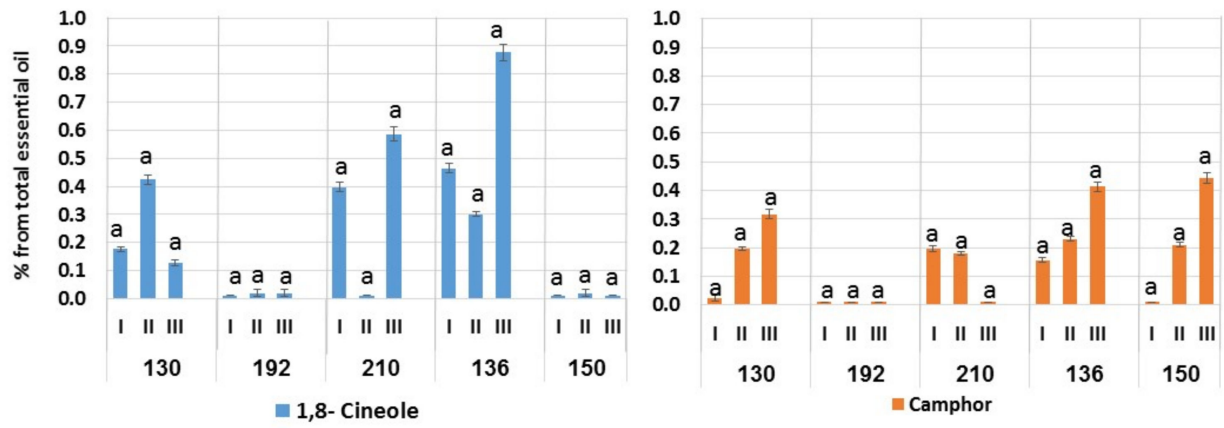

Figure 2. Dynamics of accumulation of valuable minor components in the essential oil of plants in the cultivars of A. balchanorum 130,192, 210, 136, and 150. I-vegetative stage: during the spring regrowth at the end of May 2019, the entire annual shoots were sampled; II-flower buds: the tops of the stems with closed buds were sampled in mid-October 2019; III-flowering: the tops of the stems with inflorescences were sampled in mid-November 2019. Each compound was analyzed separately in each cultivar for the differences between the stages. Bars represent standard deviation. One-way ANOVA and Student's $t$-test were applied. Levels not connected by the same letter are significantly different $(\alpha=0.05)$. 
Since cultivar 130 has such an impressive potential for natural terpene production, we performed analysis of its microcuttings propagated in vitro. However, the results were rather different from the analysis of the adult plants. Only low content of essential oils $(0.04 \%)$ enriched with three components: geranyl acetate $(70 \%)$ and two citrals (combined content of $25 \%$ ) were found in 20-day-old microcuttings. Linalool and geraniol were not detected. The dominant presence of geranyl acetate is explained by the fact that geraniol and its acetate are precursors of citral [23]. Similarly, in the adult plant, geranyl acetate is predominant during vegetative development in the spring (Figure 1). We conclude, therefore, that in vitro microcuttings remain at a very early stage of development and biosynthesis of secondary metabolites. They are not suitable for the production of essential oils but can be used for fast and efficient micropropagation. After hardening and acclimation, microcuttings will develop into adult plants, which will then serve for essential oil production. Further research is needed to establish an efficient in vitro system as the basis for commercial propagation of elite varieties of $A$. balchanorum that would allow continuous production of plant material under field conditions yielding a significant quantity of desirable compounds.

Cultivar 192 contains rather stable amounts of linalool, which remains stable during the entire growing season, from spring to late fall (Figure 1). The amount of citrals increases slightly from the vegetative to reproductive stages, while the content of geraniol peaks only in the flower bud stage to $26 \%$. The content of geranyl acetate is highest during spring regrowth $(36.2 \%)$ and then decreases to $17-18 \%$. This cultivar contains only trace amounts of 1,8-cineole and camphor (Figure 2).

The essential oil obtained from cultivar 210 during the mass flowering period was high in geraniol content (34.3\%) (Figure 1). In the vegetative plants and prior to flowering, the geraniol content was relatively low and then increased sharply during the mass flowering period. An increase in the content of geraniol during the flowering could be caused by decreased activity of geranyl dehydrogenase as proposed for Cymbopogon [23]. This line is characterized by a low linalool content but contains the valuable minor components 1,8-cineole and camphor (Figure 2).

We conclude that the seed populations of cultivars 192 and 210 contain significant amounts of linalool and geraniol, respectively, and that seed propagation can be used for the stable commercial reproduction of these lines. Two additional cultivars, 136 and 150, did not produce any dominant compounds. Their linalool content, depending on the growing stage, ranged from $20 \%$ to $36 \%$. The accumulation of citrals in both cultivars increased during the growing season, while the content of geranyl acetate decreased (Figure 1). The amount of geraniol was relatively low and ranged from $5.6 \%$ to $13 \%$ during the growing season. Both lines contain 1,8-cineole and camphor. In cultivar 136, the content of 1,8cineole decreased from $0.5 \%$ to $0.3 \%$ during the transition from the spring regrowth to the flower bud stage and then increased to $0.9 \%$ during the mass flowering period. In both lines, the camphor content increased during the growing season (Figure 2). Thus, the two cultivars with the highest oil production share similar dynamics of accumulation of dominant components and minor substances.

In general, the synthesis and accumulation of secondary metabolites are very complex processes, affected by genetic, developmental, and environmental factors [14]. Thus, the samples from Central Asia contained higher amounts of 1,8-cineole (29.9\%), $\alpha$-thujone $(11.7 \%)$, and camphor (11.2\%), but low quantities of linalool and citrals [27]. Studies by Svidenko and Rabotyagov [28] of A. balchanorum and A. taurica and their hybrids also show extremely high variation in the major secondary metabolites. Our analysis of the composition and dynamics of essential oils during the growing season of A. balchanorum confirms at least three choices for the natural production of the essential oils. Under our experimental conditions, cultivar 130 contains high amounts of citrals, while linalool dominates in cultivar 192 and geraniol in cultivar 210.

In agricultural practice, the outstanding selections of Artemisia are propagated either by seeds or vegetatively. However, neither system is not consistent. For example, seed 
propagation of A. аnпua for artemisinin extraction is employed on commercial plantations $[29,30]$, but low seed viability and germination rate impair commercial propagation. Therefore, the selection of the outstanding cultivars in the specific location should be accompanied by efficient true-to-type propagation.

Micropropagation techniques were studied in different Artemisia species. Both tissue culture-regenerated plants and rooted cuttings of $A$. annua, $A$. nilagirica, and $A$. japonica performed better than plants derived from seeds in terms of uniformity, yield, and biochemical content $[29,31,32]$. The use of in vitro technology to produce plants of $A$. balchanorum with homogeneously high essential oils will certainly improve the quality and yield of the commercial products extracted from this species but will not allow direct extraction of the desired compounds from in microcuttings.

Finally, the question of how best to extract and separate pure compounds and select for special chemotypes of lemon wormwood corresponds with the concept of the "entourage effect", better known from cannabis studies [33,34]. This effect refers to the synergistic mode of multiple compounds, which may potentiate pharmaceutical efficacy. In this context, Artemisia could be an interesting model in which to study the synergistic effects of various essential oils in aromatic plants.

\section{Materials and Methods}

\subsection{Plant Material and Micropropagation}

The selected lines of A. balchanorum (cultivars 130,192, 210,136, and 150) were obtained from the Nikita Botanical Garden (Yalta, Russia) and maintained vegetatively in the living collection (Figure 3A). In November 2016, one-seeded achene fruits were collected from each line and sown in soil immediately after harvest. Material from the 3-year-old offspring of each seed population became the source for the qualitative and quantitative analysis of the essential oils. The constituents of the essential oils in these five cultivars were studied during the 2019 growing season at three developmental stages: (1) vegetative stage: during the spring regrowth at the end of May 2019, the entire annual shoots were sampled; (2) flower buds: the tops of the stems with closed buds were sampled in mid-October 2019 (Figure 3A); and (3) flowering: the tops of the stems with inflorescences were sampled in mid-November 2019. Each sample of approximately $300 \mathrm{~g}$ contained the tops of annual stems from 6 to 9 plants of each cultivar. Plant tops were mixed and divided into three equal parts, then $5 \mathrm{~g}$ were taken from each replicate and dried to determine moisture content and dried weight. The rest of the samples were weighed and used to extract essential oil.

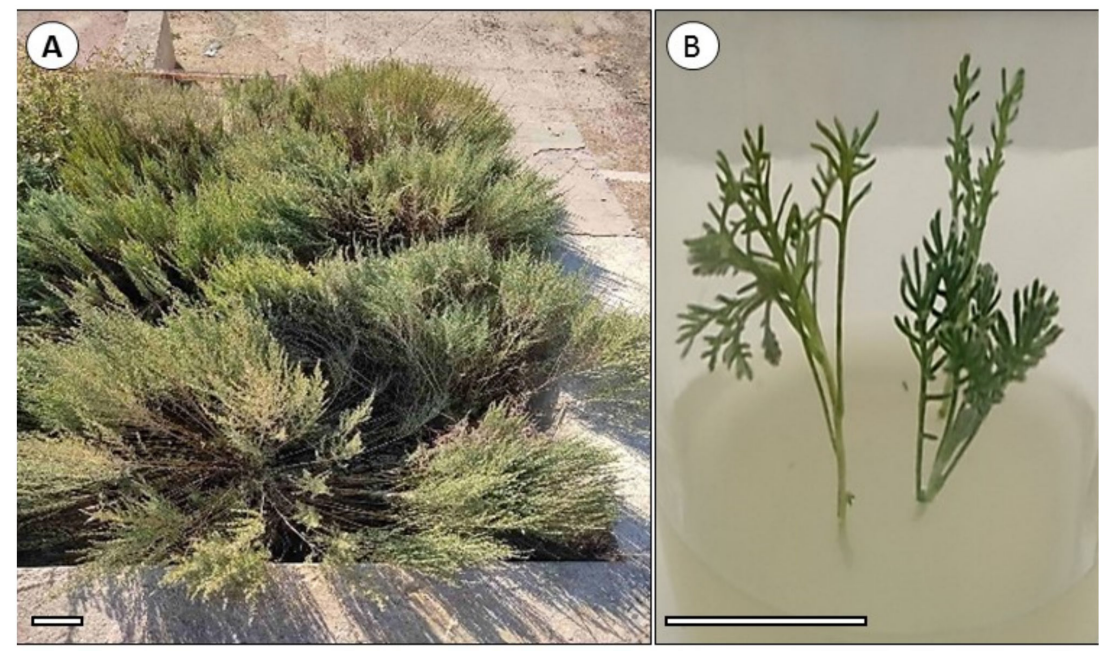

Figure 3. Plants of Artemisia balchanorum, cultivar 130; (A) 3-year-old plant in October 2019 $($ bar $=10 \mathrm{~cm}),(B)$ microcutting in vitro $($ bar $=5 \mathrm{~cm})$. 
Cultivar 130 was propagated in vitro according to a protocol proposed by Mitrofanova et al. [22]. Seeds were sterilized in 70\% alcohol for 30-40 s, treated with a $0.1 \%$ solution of diacid for $10 \mathrm{~min}$, and washed 4 times in sterile distilled water (for $10 \mathrm{~min}$ each time). The seeds were planted in test tubes on MS medium and placed in a dark chamber for $72 \mathrm{~h}$. The test tubes were then transferred to a chamber at $25^{\circ} \mathrm{C}$ with a relative humidity of $70 \%$, illumination of 5000-8000 lux, and a photoperiod of $16 \mathrm{~h}$. Young plants emerged after 1.5-2 months. Normally developed seedlings were propagated using microcuttings, i.e., the shoots were aseptically dissected into fragments about $1 \mathrm{~cm}$ in length and transferred to fresh MS medium for rooting and growth. After 25-30 days, well-developed cuttings were obtained, ready for the next cycle (Figure 3B). Twenty-day-old microcuttings were used for the extraction of essential oils.

\subsection{Chemical Analysis}

Essential oils from the adult plants and microcuttings were extracted by hydrodistillation of freshly harvested raw materials with petroleum ether, followed by recalculation of the mass fraction of the oil by raw and dry weight. Hydro-distillation was carried out with a reflux condenser, and the essential oil was collected in a Ginsberg trap. Component identification was carried out by comparison with standards (Merck, Germany); n-hexane was the zero mark.

The oil of each replicate was separated into components to determine its qualitative and quantitative composition. The average value of the total number of components in the essential oil was calculated. The separation of essential oils into components was carried out using standard gas-liquid chromatography on a model 3700 chromatograph (St.-Petersburg, Russia) on a $50 \mathrm{~m}$ long quartz capillary column (SE-52 phase; ID, $0.25 \mathrm{~mm}$; carrier gas, nitrogen; flow rate, $\mu \mathrm{L} / \mathrm{min}$ ). The temperature of the evaporator and detector was $220^{\circ} \mathrm{C}$. The initial temperature of the thermostat was $80^{\circ} \mathrm{C}$, which increased to $170{ }^{\circ} \mathrm{C}$ following a subsequent increase of $3{ }^{\circ} \mathrm{C} / \mathrm{min}$ for $30 \mathrm{~min}$. Identification of components was carried out by comparison to internal standards. Sampling was carried out in triplicate for each growing season, and essential oils were obtained from each repetition.

\subsection{Statistical Analysis}

One-way and two-way ANOVA, as well as Student's $t$-test $(\alpha=0.05)$ analyses, were applied, using JMP-Pro, Statistical Discovery, version 15, SAS Institute.

\section{Conclusions}

Three distinct cultivars of $A$. balchanorum with a high content of citral, linalool, and geraniol were found as valuable sources for natural essential oils. The seed populations of these cultivars maintain distinct dynamics of the dominant and valuable minor components during annual development. Further selection and efficient clonal micropropagation will allow mass reproduction of valuable cultivars and promising forms of A. balchanorum on a commercial scale.

The combined effect of the secondary metabolites ("entourage effect") can be more effective in the whole composition rather than in single components. Further development of agronomical systems and technologies for uniform propagation will allow for the use of valuable compounds as insect repellents and anti-antimicrobial, as well as in cosmetics and the food industry.

Supplementary Materials: The following are available online at https://www.mdpi.com/article/10 .3390/ plants11010006/s1; Table S1. Composition of essential oil (\%) in A. balchanorum cultivar 130 at various stages of development and in vitro propagated plantlets. I, vegetative; II, flower buds; III, full flowering; Table S2. Composition of the essential oils (\%) in the offspring of four cultivars of A. balchanorum at three developmental stages: I-vegetative; II-flower buds; III-full flowering; Table S3. Analysis of variances by Two-Way ANOVA for five dominant and two minor compounds of Artemisia balchanorum essential oil. Most compounds show significant statistical interaction between the cultivar and the developmental stage $(\alpha=0.05)$. 


\begin{abstract}
Author Contributions: Conceptualization and methodology, G.V.K. and E.S.-M.; resources, L.A.K.; writing-original draft preparation, G.V.K. and R.K.-G.; writing-review and editing, R.K.-G. and E.S.-M.; visualization, R.K.-G. All authors have read and agreed to the published version of the manuscript.
\end{abstract}

Funding: Grant 2019-220-07-5322 of the Ministry of Science and Higher Education of the Russian Federation.

Conflicts of Interest: The authors declare no conflict of interest.

\title{
References
}

1. Gruessner, B.M.; Cornet-Vernet, L.; Desrosiers, M.; Lutgen, P.; Towler, M.J.; Weathers, P.J. It is not just artemisinin: Artemisia sp. for treating diseases including malaria and schistosomiasis. Phytochem. Rev. 2019, 18, 1509-1527. [CrossRef] [PubMed]

2. Nigam, M.; Atanassova, M.; Mishra, A.P.; Pezzani, R.; Devkota, H.P.; Plygun, S.; Salehi, B.; Setzer, W.N.; Sharifi-Rad, J. Bioac-tive compounds and health benefits of Artemisia species. Nat. Prod. Commun. 2019, 14, 11.

3. Koul, B.; Taak, P.; Kumar, A.; Khatri, T.; Sanyal, I. The Artemisia genus: A review on traditional uses, phytochemical constituents, pharmacological properties and germplasm conservation. J. Glycom. Lipidom. 2018, 7, 1-7. [CrossRef]

4. $\quad$ Rashid, M.U.; Alamzeb, M.; Ali, S.; Ullah, Z.; Shah, Z.A.; Naz, I.; Khan, M.R. The chemistry and pharmacology of alkaloids and allied nitrogen compounds from Artemisia species: A review. Phytother. Res. 2019, 33, 2661-2684. [CrossRef]

5. Trendafilova, A.; Moujir, L.M.; Sousa, P.M.C.; Seca, A.M.L. Research advances on health effects of edible Artemisia species and some sesquiterpene lactones constituents. Foods 2021, 10, 65. [CrossRef]

6. Radulović, N.S.; Blagojević, P.D. Average mass scan of the total ion chromatograms: A new gas chromatography-mass spectrometry derived variable for fast and reliable multivariate statistical treatment of essential oil compositional data. J. Chromatogr. A 2013, 1301, 190-199. [CrossRef]

7. Al-Snafi, A.E. Oils and fats contents of medicinal plants, as natural ingredients for many therapeutic purposes-A review. IOSR J. Pharm. 2020, 10, 1-41.

8. Sharmeen, J.B.; Mahomoodally, F.M.; Zengin, G.; Maggi, F. Essential oils as natural sources of fragrance compounds for cosmetics and cosmeceuticals. Molecules 2021, 26, 666. [CrossRef]

9. Liu, X.; Cai, J.; Chen, H.; Zhong, Q.; Hou, Y.; Chen, W.; Chen, W. Antibacterial activity and mechanism of linalool against Pseudomonas aeruginosa. Microb. Pathog. 2020, 141, 103980. [CrossRef]

10. Lei, Y.; Fu, P.; Jun, X.; Cheng, P. Pharmacological properties of geraniol-A review. Planta Med. 2018, 85, 48-55. [CrossRef]

11. Chizzola, R. Regular monoterpenes and sesquiterpenes (essential oils). In Natural Products; Ramawat, K., Mérillon, J.M., Eds.; Springer: Berlin/Heidelberg, Germany, 2013; pp. 2973-3008. [CrossRef]

12. Chen, W.; Viljoen, A. Geraniol-A review of a commercially important fragrance material. S. Afr. J. Bot. 2010, 76, 643-651. [CrossRef]

13. Figueiredo, A.C.; Barroso, L.G.; Pedro, J.G.; Scheffer, J.J.C. Factors affecting secondary metabolite production in plants: Volatile components and essential oils. Flavour Fragr. J. 2008, 23, 213-226. [CrossRef]

14. Li, Y.; Kong, D.; Fu, Y.; Sussman, M.R.; Wu, H. The effect of developmental and environmental factors on secondary metabolites in medicinal plants. Plant Physiol. Biochem. 2020, 148, 80-89. [CrossRef] [PubMed]

15. Cosge Şenkal, B.; Kiralan, M.; Yaman, C. The Effect of different harvest stages on chemical composition and antioxidant capacity of essential oil from Artemisia annua L. Tarm Bilim. Derg. 2014, 21, 71. [CrossRef]

16. Howyzeh, M.S.; Noori, S.A.S.; Shariati, J.V. Essential oil profiling of Ajowan (Trachyspermum ammi) industrial medicinal plant. Ind. Crop. Prod. 2018, 119, 255-259. [CrossRef]

17. Egamberdieva, D.; Jabborova, D. Medicinal plants of Uzbekistan and their traditional uses. In Vegetation of Central Asia and Environs; Egamberdieva, D., Öztürk, M., Eds.; Springer Nature: Cham, Switzerland, 2018; pp. 211-237. [CrossRef]

18. Rabotyagov, V.D.; Isikov, V.P.; Ovcharenko, N.S. Variability of the component composition of essential oil in Artemisia bal-chanorum Krasch. plants infected with the rust fungus Puccinia absinthii DC. Physiol. Biochem. Cult. Plants 2011, 5, 419-424.

19. Svidenko, L.V. Results of introduction and selection of Artemisia balchanorum Krasch. in the steppe zone of southern Ukraine. Proc. Nikita Bot. Gard. 2011, 133, 209-220.

20. Kotikov, I.V.; Khodakov, G.V. Lipids from the aboveground part of the plant Artemisia balchanorum Krasch. Scientific notes of the Crimean Federal University named after Vernadsky. Biol. Chem. 2013, 2, 222-225.

21. Jirgalova, E.A. Methods of Reproduction of Lemon Wormwood in the Conditions of the Central Zone of the Republic of Kalmykia; Collection of Scientific Works of Young Scientists, Postgraduates and Students of the Kalmyk State University; Elista: Kalmykia, Russia, 2004; pp. 10-13. (In Russian)

22. Mitrofanova, O.V.; Logvinenko, I.E.; Ivanova, N.N. Regeneration of Plants from Isolated Organs and Tissues of Artemisia balchanorum Krasch. and Artemisia scoparia W. K; Nikita Botanical Garden: Yalta, Russia, 1997; Volume 119, pp. 7-34. (In Russian)

23. Ganjewala, D.; Luthra, R. Essential oil biosynthesis and regulation in the genus Cymbopogon. Nat. Prod. Commun. 2010, 5, 163-172. [CrossRef]

24. Logvinenko, L.A.; Shevchuk, O.M. The citral form of Artemisia santonica L. f. citralifera N. Rubtz. Zemledelie 2020, 7, 16-20. (In Russian) [CrossRef] 
25. Ganjewala, D.; Gupta, A.K.; Muhury, R. An update on bioactive potential of a monoterpene aldehyde citral. J. Biol. Act. Prod. Nat. 2012, 2, 186-199. [CrossRef]

26. Pereira, I.; Severino, P.; Santos, A.C.; Silva, A.; Souto, E.B. Linalool bioactive properties and potential applicability in drug delivery systems. Colloids Surf. B Biointerfaces 2018, 171, 566-578. [CrossRef]

27. Basher, K.H.C.; Özek, T.; Demirchakmak, B.; Nuriddinov, K.R.; Abduganiev, B.Y.; Aripov, K.N.; Khodzimatov, K.K.; Nigmatullaev, O.A.; Shamyanov, E.D. Essential oils of some Artemisia species from Central Asia. Chem. Nat. Compd. 1997, 33, 293-295. [CrossRef]

28. Svidenko, L.V.; Rabotyagov, V.D. Study of biochemistry hybrids of Artemisia and their initial species in conditions of the Kherson region. Plant Introd. 2003, 1-2, 117-121. (In Russian)

29. Wetzstein, H.Y.; Porter, J.A.; Janick, J.; Ferreira, J.F.S.; Mutui, T.M. Selection and clonal propagation of high artemisinin genotypes of Artemisia annua. Front. Plant Sci. 2018, 9, 358. [CrossRef]

30. Manish, D. Seed physiology and germination in sweet wormwood (Artemisia annua L.). Med. Plants-Int. J. Phytomed. Relat. Ind. 2016, 8, 244-248.

31. Shinde, S.; Sebastian, J.K.; Jain, J.R.; Hanamanthagouda, M.S.; Murthy, H.N. Efficient in vitro propagation of Artemisia nilagirica var. nilagirica (Indian wormwood) and assessment of genetic fidelity of micropropagated plants. Physiol. Mol. Biol. Plants 2016, 22, 595-603. [CrossRef]

32. Shinde, S.; Katewal, P.R.; Shanbhag, D.D.; Joseph, K.S.; Murthy, H.N. In vitro propagation of Artemisia japonica. J. Herbs Spices Med. Plants 2017, 23, 36-43. [CrossRef]

33. Ribeiro, S. Whole organisms or pure compounds? Entourage effect versus drug specificity. Phytother. Res. 2019, 33, 2661-2684.

34. Koltai, H.; Namdar, D. Cannabis phytomolecule 'entourage': From domestication to medical use. Trends Plant Sci. 2020, 25, 976-984. [CrossRef] 